\title{
Correction to: 3D quantification of in vivo orthodontic tooth movement in rats by means of micro-computed tomography
}

\author{
Maria Cadenas de Llano-Perula ${ }^{1}$. Chen Zong ${ }^{1}$. Jeroen Van Dessel ${ }^{2}$ - Anne Marie Kuijpers-Jagtman ${ }^{3,4,5}$. \\ Guy Willems ${ }^{1}$
}

Published online: 5 March 2022

○) Springer-Verlag GmbH Germany, part of Springer Nature 2022

\section{Correction to: Clinical Oral Investigations https://doi.org/10.1007/s00784-021-04358-w}

In the published article, the author information is missing: Maria Cadenas de Llano-Pérula and Chen Zong contributed equally to this work and would like to share first authorship.

The original article has been corrected.

Publisher's note Springer Nature remains neutral with regard to jurisdictional claims in published maps and institutional affiliations.

The original article can be found online at https://doi.org/10.1007/ s00784-021-04358-w.

Maria Cadenas de Llano-Perula

maria.cadenas@uzleuven.be

1 Department of Oral Health Sciences - Orthodontics, KU Leuven and University Hospitals Leuven, Kapucijnenvoer 7, blok A, bus 7001, 3000 Leuven, Belgium

2 Oral and Maxillofacial Surgery, University Hospitals Leuven and OMFS-IMPATH Research Group, Department of Imaging \& Pathology, Faculty of Medicine, KU Leuven, Leuven, Belgium

3 Department of Orthodontics and Dentofacial Orthopedics, School of Dental Medicine/Medical Faculty, University of Bern, Bern, Switzerland

4 Department of Orthodontics, University Medical Center Groningen, University of Groningen, Groningen, The Netherlands

5 Faculty of Dentistry, Universitas Indonesia, Jakarta, Indonesia 